\title{
Uncertainties in Projecting Future Changes in Atmospheric Rivers and Their Impacts on Heavy Precipitation over Europe $\mathscr{O}$
}

\author{
YANG GAO, JiAn LU, AND L. RUBy LEUNG \\ Atmospheric Sciences and Global Change Division, Pacific Northwest National Laboratory, Richland, Washington
}

(Manuscript received 22 January 2016, in final form 5 May 2016)

\begin{abstract}
This study investigates the North Atlantic atmospheric rivers (ARs) making landfall over western Europe in the present and future climate from the multimodel ensemble of phase 5 of the Coupled Model Intercomparison Project (CMIP5). Overall, CMIP5 captures the seasonal and spatial variations of historical landfalling AR days, with the large intermodel variability strongly correlated with the intermodel spread of historical near-surface westerly jet position. Under representative concentration pathway 8.5 (RCP8.5), AR frequency is projected to increase significantly by the end of this century, with $127 \%-275 \%$ increase at peak AR frequency regions $\left(45^{\circ}-55^{\circ} \mathrm{N}\right)$. While thermodynamics plays a dominant role in the future increase of ARs, wind changes associated with the midlatitude jet shifts also significantly contribute to AR changes, resulting in dipole change patterns in all seasons. In the North Atlantic, the model-projected jet shifts are strongly correlated with the simulated historical jet position. As models exhibit predominantly equatorward biases in the historical jet position, the large poleward jet shifts reduce AR days south of the historical mean jet position through the dynamical connections between the jet positions and AR days. Using the observed historical jet position as an emergent constraint, dynamical effects further increase future AR days over the equatorward flank above the increases from thermodynamical effects. Compared to the present, both total and extreme precipitation induced by ARs in the future contribute more to the seasonal mean and extreme precipitation, primarily because of the increase in AR frequency. While AR precipitation intensity generally increases more relative to the increase in integrated vapor transport, AR extreme precipitation intensity increases much less.
\end{abstract}

\section{Introduction}

Atmospheric rivers (ARs) are narrow corridors of water vapor, usually with a length of $2000 \mathrm{~km}$ or more, that account for over $90 \%$ of the meridional moisture transport associated with storm tracks in the extratropical atmosphere (Zhu and Newell 1998). During winter, the AR-induced precipitation could account for $15 \%-30 \%$ of the total precipitation in Europe and western United States (Lavers and Villarini 2015). In northwestern United States, ARs contribute to $25 \%-45 \%$ of extreme

Supplemental information related to this paper is available at the Journals Online website: http://dx.doi.org/10.1175/JCLI-D-160088.s1.

Corresponding author address: Dr. Yang Gao, Pacific Northwest National Laboratory, Atmospheric Science and Global Change, 902 Battelle Blvd., Richland, WA 99354.

E-mail: yang.gao@pnnl.gov; ruby.leung@pnnl.gov precipitation depending on the geographical locations (Rutz et al. 2014). Because of their importance to floods and water resources, ARs have been extensively studied during the last decade (Ralph et al. 2006; Leung and Qian 2009; Neiman et al. 2011; Ralph and Dettinger 2012; Gao et al. 2015; Hagos et al. 2015; Lavers and Villarini 2015).

As prominent features over the Pacific Ocean, ARs that make landfall on the west coast of North America have been investigated both in the context of historical climatology and extreme events (Ralph et al. 2006; Neiman et al. 2011; Ralph and Dettinger 2012) and future changes under climate warming (Payne and Magnusdottir 2014; Gao et al. 2015). Neiman et al. (2008) and Gao et al. (2015) found higher number of ARs in the cool (warm) season in the southern (northern) coastal area of North America. Changes in AR frequency in the future are closely related to changes in water vapor as well as atmospheric circulation, both strongly modulated by global warming (Barnes and Polvani 2013). In particular, changes in the winds associated with AR moisture 
transport were found to predominantly counter the effects of increasing water vapor that substantially increases the frequency of landfalling ARs in western North America (Gao et al. 2015). However, with a poleward shift of the storm tracks, wind changes could also increase AR days in the high latitudes such as coastal Alaska in spring time.

In the North Atlantic, Lavers et al. (2013) investigated the dynamical and thermodynamical modulations of future landfalling ARs in the United Kingdom $\left(50^{\circ}-60^{\circ} \mathrm{N}\right)$ and found that the increase of future winter ARs is mainly a result of thermodynamical effect whereas dynamical effect plays very little role. However, similar to AR frequency in western North America, the number of AR days in western Europe could vary dramatically by seasons and locations. Thus, to fully understand the changes of North Atlantic ARs that make landfall in Europe and the driving mechanism, this study investigates the seasonal changes in AR days and extreme precipitation across the entire coastal area in western Europe. Using a multimodel ensemble (MME) of climate projections, uncertainty in projecting the changes in AR days is investigated, with the goal of exploring a potential emergent constraint on AR changes for more robust future projections.

In what follows, we first investigate the seasonality of landfalling ARs over Europe and examine the sources of the intermodel spread of AR days in the CMIP5 MME. Using outputs from the same set of models, the projected changes of the number of AR days under climate warming and the thermodynamical and dynamical modulations of the AR changes are evaluated. Last, the total and extreme precipitation associated with ARs and the future changes are discussed.

\section{Data and method}

In this study, the same 24 CMIP5 models used by Gao et al. (2015) and listed in Table S1 of the supplementary material are analyzed for the historical period of 1975-2004 and future period of 2070-99 under the representative concentration pathway 8.5 (RCP8.5) scenario (Moss et al. 2010; van Vuuren et al. 2011). Details regarding the CMIP5 data and the four reanalysis data used for model evaluation are discussed in Text S1 in the supplementary material of Gao et al. (2015). To summarize briefly, outputs from one member for each CMIP5 model are interpolated to a $1.25^{\circ}$ latitude by $1.875^{\circ}$ longitude grid. To evaluate how well the CMIP5 models capture the seasonal variations of ARs, four reanalysis datasets are used in this study-the National Centers for Environmental Prediction-National Center for Atmospheric Research (NCEP-NCAR) Reanalysis-1 (NCEP1; Kalnay et al. 1996), the NCEP

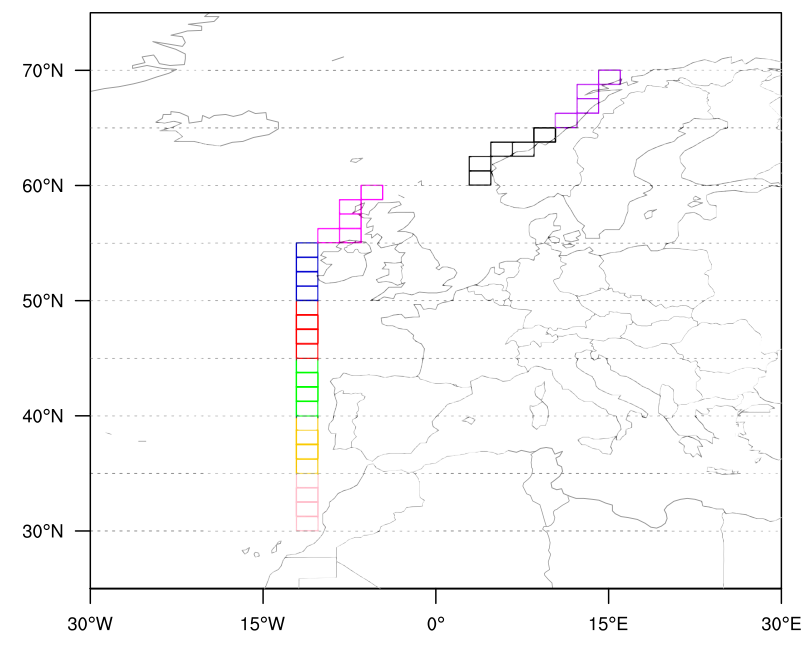

FIG. 1. The grids used to detect atmospheric rivers. The colorcoded squares are the grid cells used to detect ARs, with different colors indicating different latitudinal bins, which are also separated by the dashed gray lines.

Climate Forecast System Reanalysis (CFSR; Saha et al. 2010), the European Centre for Medium-Range Weather Forecasts (ECMWF) interim reanalysis (ERA-Interim; Dee et al. 2011), and the Modern-Era Retrospective Analysis for Research and Applications (MERRA; Rienecker et al. 2011) - and the common period of these four datasets (1979-2004) is used for evaluating the 30-yr historical simulation of ARs in CMIP5 (1975-2004). Using the period 1979-2004 for CMIP5 historical AR statistics does not lead to any appreciable difference. For consistency, all reanalysis data are also interpolated to the $1.25^{\circ}$ latitude by $1.875^{\circ}$ longitude grid. Variables used in this study mainly include daily mean temperature, specific humidity, zonal and meridional winds from 1000 to $500 \mathrm{hPa}$, and daily total precipitation from CMIP5 and the reanalysis data.

The vertically integrated vapor transport (IVT) is estimated by integrating the moisture transport between the 1000- and 500-hPa pressure levels as

$$
\mathrm{IVT}=\sqrt{\left(\frac{1}{g} \int_{1000}^{500} q u d p\right)^{2}+\left(\frac{1}{g} \int_{1000}^{500} q v d p\right)^{2}},
$$

where $g$ represents the gravitational acceleration, $q$ represents the layer mean specific humidity, $u$ represents zonal wind, and $v$ represents meridional wind.

Following Lavers et al. (2012), Lavers and Villarini (2013), and Gao et al. (2015), we first identify ARs that make landfall in the west coast of Europe between $30^{\circ}$ and $70^{\circ} \mathrm{N}$. The coastal grids, indicated by the colored grid cells in Fig. 1, are grouped into eight bins shown by the different colors separated by the gray dashed lines for each $5^{\circ}$ latitudinal band. Daily IVT was computed first; on each 
day, the grid cell with the maximum IVT along the west coast of Europe was recorded, and the 85th percentile of IVT in each bin was determined as the threshold for that bin. The 85 th percentile was suggested by Lavers et al. (2012) as it represents the median IVT value of the observed AR events based on Neiman et al. (2008) and has also been adopted by several other studies (Payne and Magnusdottir 2014; Gao et al. 2015; Payne and Magnusdottir 2015). The 85th percentile at present was applied individually to all reanalysis and CMIP5 models (both present and future climate). The thresholds at each latitudinal bin are listed in Table S2 in the supplementary material for both CMIP5 models and reanalysis datasets. On average, the thresholds in CMIP5 range from 313 to $454 \mathrm{~kg} \mathrm{~m}^{-1} \mathrm{~s}^{-1}$, somewhat smaller than the corresponding values from the reanalysis datasets (ranging from 353 to $463 \mathrm{~kg} \mathrm{~m}^{-1} \mathrm{~s}^{-1}$ ). The thresholds are relatively higher at the bin between $40^{\circ}$ and $55^{\circ} \mathrm{N}$ compared to both lower and higher latitudes. Note also the considerable spread of IVT thresholds even among the four reanalysis datasets. If the IVT in the recorded grid cell exceeds the threshold of its corresponding bin, an upstream (northwest-west-southwest-south) and downstream (north-northeast-east-southeast) search is performed. The search continues until none of the adjacent grids exceeds the IVT threshold. If the total length of the detected area exceeds $2000 \mathrm{~km}$ (Ralph et al. 2004; Neiman et al. 2008), and the mean vertically integrated water vapor (IWV) over the path is greater than $2 \mathrm{~cm}$ as well, all the grids within the area are defined to have an AR day. With the 85th percentile threshold, a maximum of $14 \mathrm{AR}$ days per season is possible for the present climate so it is important to include the constraints of other criteria such as the length and IWV threshold to yield comparable AR statistics with observed values. We also tested the sensitivity of AR detection to integrating water vapor transport from 1000 to $10 \mathrm{hPa}$ and found no qualitative difference in both the climatological mean frequency of ARs and their changes in response to RCP8.5 climate change forcing.

\section{Results}

\section{a. Historical number of AR days in CMIP5}

To gain confidence in how well the CMIP5 models are able to simulate North Atlantic ARs, the seasonal total number of AR days simulated across the eight bins over the coastal area in Europe is compared with four reanalysis datasets, shown in Fig. 2. Similar to ARs in eastern Pacific, ARs occur more frequently in fall and winter along the European coast, with a maximum of about 3-4 AR days between $45^{\circ}$ and $50^{\circ} \mathrm{N}$, while spring has the lowest likelihood for AR occurrence. Overall, the latitudinal variations in the CMIP5 MME mean correspond relatively well with the reanalysis data across the four seasons. However, there is significant intermodel spread and the CMIP5 models overestimate and underestimate the number of ARs in a few locations and seasons, with the most prominent overestimation occurring over the $35^{\circ}-40^{\circ} \mathrm{N}$ bin during the winter.

Since ARs are features arising from concentrated large water vapor transport, biases in both moisture and wind could be responsible for the aforementioned over- or underestimation of AR frequency. First, the intermodel spread and model-reanalysis difference in the upstream IWV (averaged in the box $20^{\circ}-60^{\circ} \mathrm{N}, 60^{\circ}-15^{\circ} \mathrm{W}$ ) are examined with those in the AR frequency. For all seasons, we found weak or no correlation between the intermodel spread of the vertically integrated water vapor (as well as the near-surface temperature via the Clausius-Clapeyron relation) and the historical number of ARs, especially for the areas with larger model biases (hence not shown). On the contrary, there are significant correlations between the historical AR numbers and the speed and position of the near-surface westerly jet. As the near-surface westerly is the wind that the surface friction acts upon to balance the vertically integrated eddy momentum forcing, its meridional structure represents of that of the eddy-driven jet (e.g., Woollings et al. 2010). Hereafter, this near-surface expression of the eddy-driven jet will be referred to as jet for brevity. One should not confuse it with the thermally forced subtropical jet (which is always centered around $30^{\circ}$ latitude) in the upper troposphere. The speed and position of the jet are defined as the maximum of the seasonal mean $850-\mathrm{hPa}$ zonal wind averaged between $30^{\circ} \mathrm{W}$ and $10^{\circ} \mathrm{E}$ and the corresponding latitude, respectively. Focusing on the winter season when the biases and intermodel spreads are the largest (Fig. 3), we find that the mean winter jet position from the four reanalysis is around $53^{\circ} \mathrm{N}$, but the CMIP5 jet position ranges from $41^{\circ}$ to $54^{\circ} \mathrm{N}$ with a mean position at $48^{\circ} \mathrm{N}$, showing an evident equatorward bias. There are distinct relationships between $\mathrm{AR}$ days and jet position between the latitudinal bins at the two flanks of the mean jet position. South of the CMIP5 mean jet position $\left(40^{\circ}-45^{\circ} \mathrm{N}\right.$; Fig. 3a), models that have larger equatorward biases in the jet position simulate more ARs. Conversely, north of the CMIP5 mean jet position (i.e., $50^{\circ}-55^{\circ} \mathrm{N}$; Fig. $3 \mathrm{c}$ ), models with more poleward jet position simulate more ARs. The identical but opposite slopes from linear regression of AR days on jet position in the two regions suggest an opposite response of AR days to the jet position in the models. For the latitude bin $\left(45^{\circ}-50^{\circ} \mathrm{N}\right.$; Fig. $\left.3 \mathrm{~b}\right)$ that coincides with the mean CMIP5 jet position, AR frequency shows a weak 

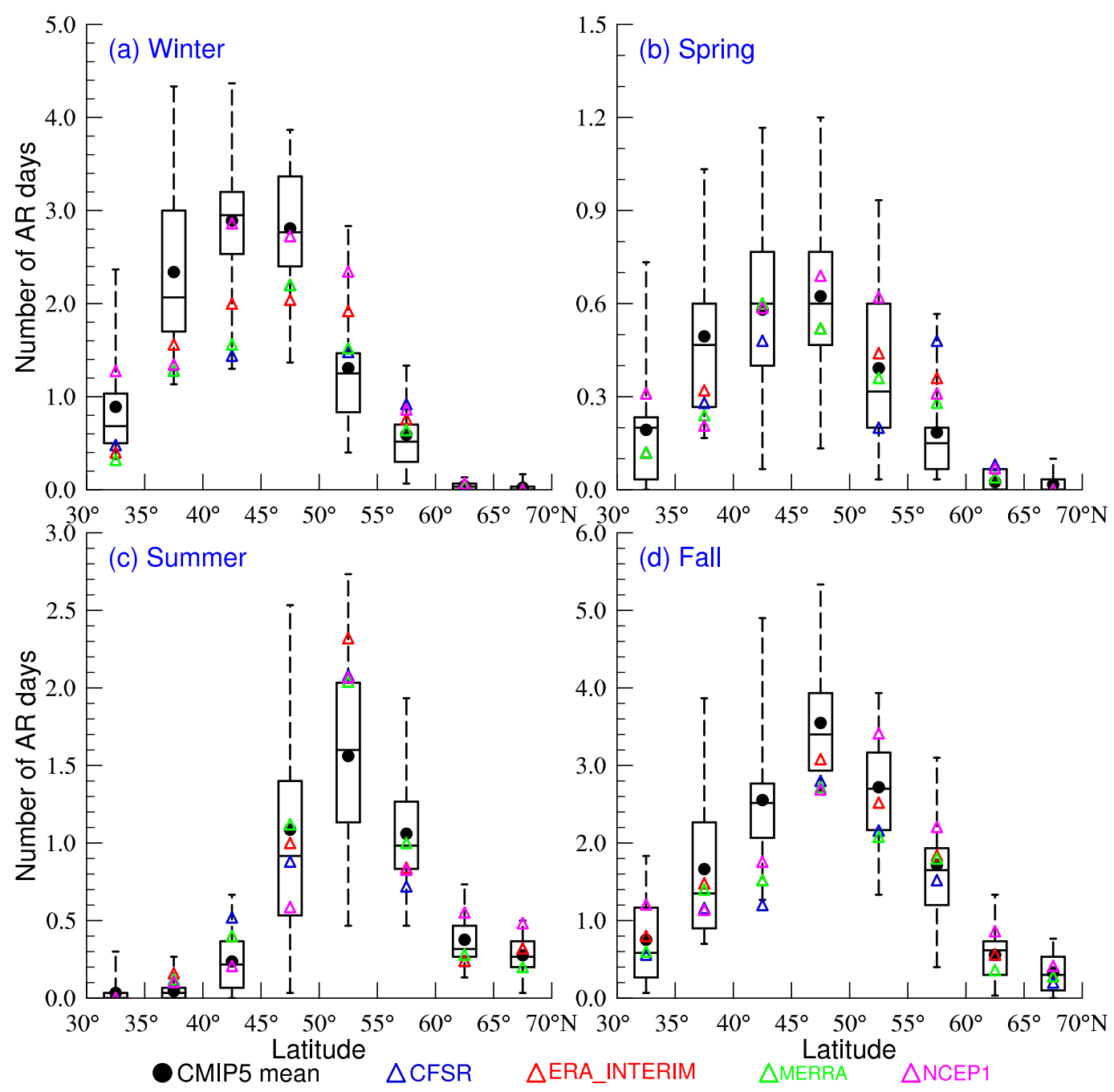

FIG. 2. Box-and-whisker plots of the number of atmospheric river days in each season from $30^{\circ}$ to $70^{\circ} \mathrm{N}$ for each of the eight bins from CMIP5 models from 1975 to 2004. The horizontal line within the box indicates the CMIP5 median, the bottom and top boundaries of the box indicate the 25th and 75th percentile, and the whiskers indicate the highest and lowest values of the results from CMIP5. The dot inside the box indicates the CMIP5 MME mean. The number of atmospheric rivers from the four reanalysis datasets is marked with triangles for CFSR (blue), ERAInterim (red), MERRA (green), and NCEP1 (magenta) during 1979-2004.

relationship with jet position, but correlates more strongly with the jet speed. Hence the overestimation (underestimation) of AR days between $40^{\circ}$ and $45^{\circ} \mathrm{N}$ $\left(50^{\circ}-55^{\circ} \mathrm{N}\right)$ in Fig. 2a is largely attributable to the equatorward biases in the CMIP5 jet position, while the overestimation of jet speed contributes to the overestimation of AR days between $45^{\circ}$ and $50^{\circ} \mathrm{N}$. Similar relationships are also found for the fall and spring (Figs. S3 and S1, respectively, in the supplementary material) seasons. Given the conspicuous model bias in the winter jet speed and position as well as the related bias in the AR occurrence, extra caution is advised in interpreting the projection of the future $\mathrm{AR}$ changes made by the CMIP5 models. As to be elaborated later in section 3c, a calibration on the CMIP5 projection is proposed based on the emergent constraint on the eddy-driven midlatitude circulation. In summer (Fig. S2 in the supplementary material), the mean CMIP5 jet position $\left(52^{\circ} \mathrm{N}\right)$ is similar to that of the four reanalyses, so the AR days are more tightly correlated with jet speed instead of position.

\section{b. Thermodynamical and dynamical contributions to changes in AR days in the future}

To investigate the impact of climate change on landfalling ARs, Fig. 4 shows the number of AR days at present (1975-2004; black) and future climate conditions under RCP8.5 (2070-99; red), with the percentage 

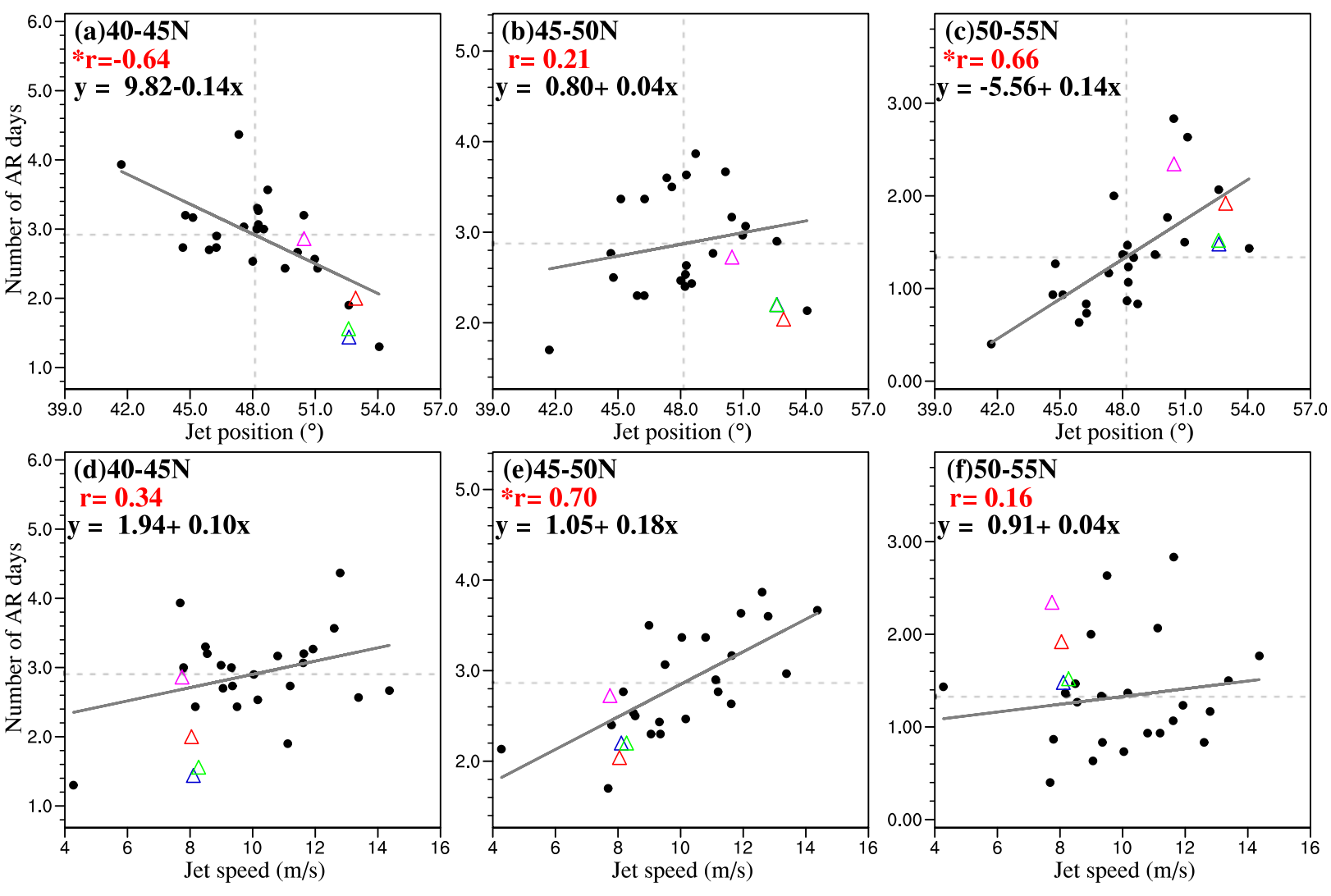

CMIP5

$\triangle$ CFSR

$\triangle$ ERA_INTERIM

$\triangle$ MERRA

$\triangle$ NCEP1

FIG. 3. Historical number of AR days vs (a)-(c) jet position and (d)-(f) speed in winter for three latitudinal bins from $40^{\circ}$ to $55^{\circ} \mathrm{N}$. The jet speed and position are defined as the maximum of the seasonal mean 850 -hPa zonal wind averaged between $30^{\circ} \mathrm{W}$ and $10^{\circ} \mathrm{E}$ and the corresponding latitude, respectively. Each black dot corresponds to one CMIP5 model whereas the triangles of different colors denote the reanalysis datasets. An asterisk next to the correlations shown in red indicates it is statistically significant. The dashed line indicates multimodel mean (i.e., mean number of AR days or jet position). The solid gray line represents the least squares regression line between the number of AR days and jet position/speed, with equations listed on the top left.

change (RCP8.5 minus present divided by present) indicated by the numbers across the top in each panel. A majority of coastal areas show significant increases in the number of AR days by a few times $(127 \%-275 \%$ increase at peak $\mathrm{AR}$ frequency regions: $\left.45^{\circ}-55^{\circ} \mathrm{N}\right)$ under warming. The location of peak AR frequency $\left(45^{\circ}-55^{\circ} \mathrm{N}\right)$ corresponds to the CMIP5 mean jet position, consistently for all seasons in both current and future climate.

To investigate the thermodynamical and dynamical contributions to the increase of AR days, a scaling method is used to separate the effects of changes in water vapor and winds that influence the IVT following Gao et al. (2015). We rescale the daily IWV in the present climate by a factor of $q_{\mathrm{m} 2} / q_{\mathrm{m} 1}$, where $q_{\mathrm{m} 1}$ and $q_{\mathrm{m} 2}$ are the 30 -yr seasonal mean IWV averaged over the eastern North Atlantic basin $\left(20^{\circ}-60^{\circ} \mathrm{N}, 60^{\circ}-15^{\circ} \mathrm{W}\right)$ for the present and future, respectively. This is equivalent to assuming the increase of water vapor at synoptic scales follows the same ratio of increase of the seasonal mean water vapor; as such it neglects the correlation effect between wind and water vapor at high frequency. The resultant time series of IVT represents a hypothetical scenario in which the present wind advects the water vapor of the RCP8.5 warm climate, a scenario denoted by $V_{1} \bar{Q}_{2}$ symbolically. The ARs detection is then applied to the rescaled IVT for each CMIP5 model using the same 85th percentile threshold based on the present distribution of IVT. The resultant AR days are shown by the blue lines in Fig. 4. Contrasting the scenario $V_{1} \bar{Q}_{2}$ against the AR distribution of the present climate (i.e., $V_{1} Q_{1}$ ) reveals the thermodynamic contributions to the change in AR days due to the increase of water vapor; these, in a fractional form, are enumerated by the numbers in the second row in Fig. 4. Comparing with the fractional change between the future $\left(V_{2} Q_{2}\right)$ and present $\left(V_{1} Q_{1}\right)$ climates (displayed by numbers in the first row in each panel), the thermodynamic rescaling tends to show a larger (smaller) increase of AR days for the 


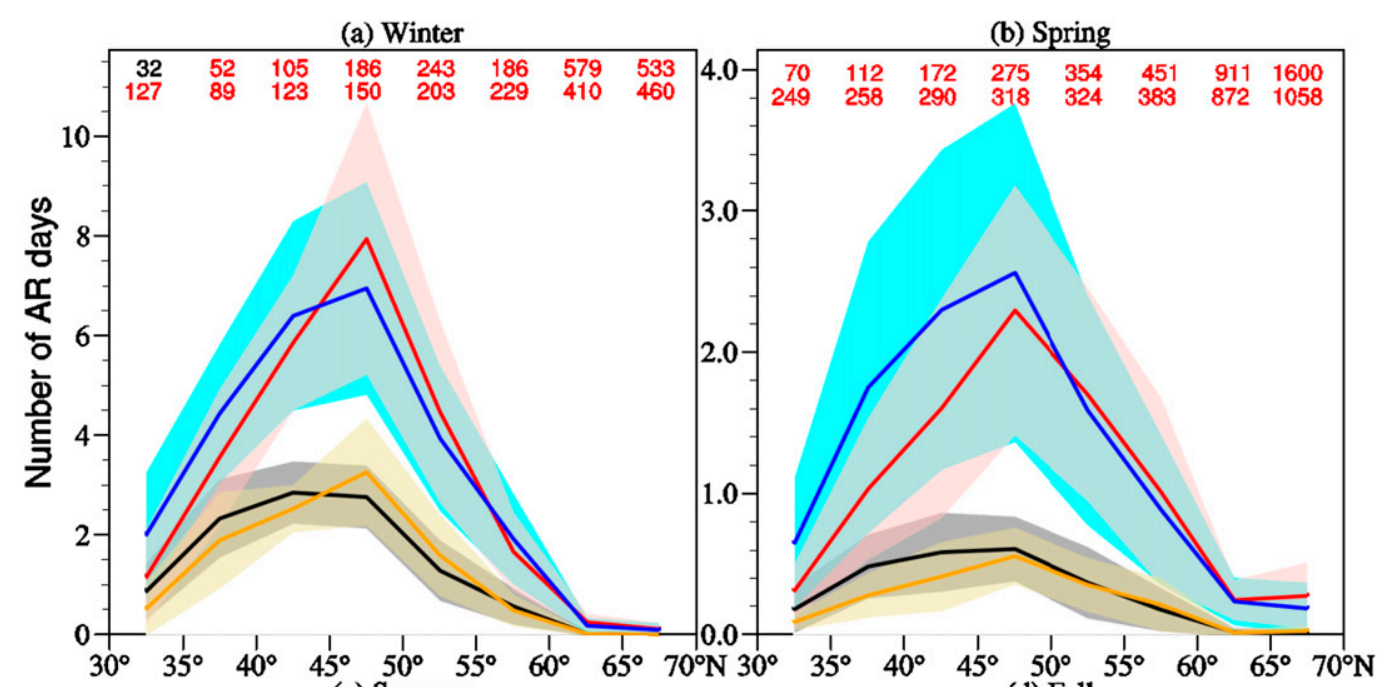

(c) Summer
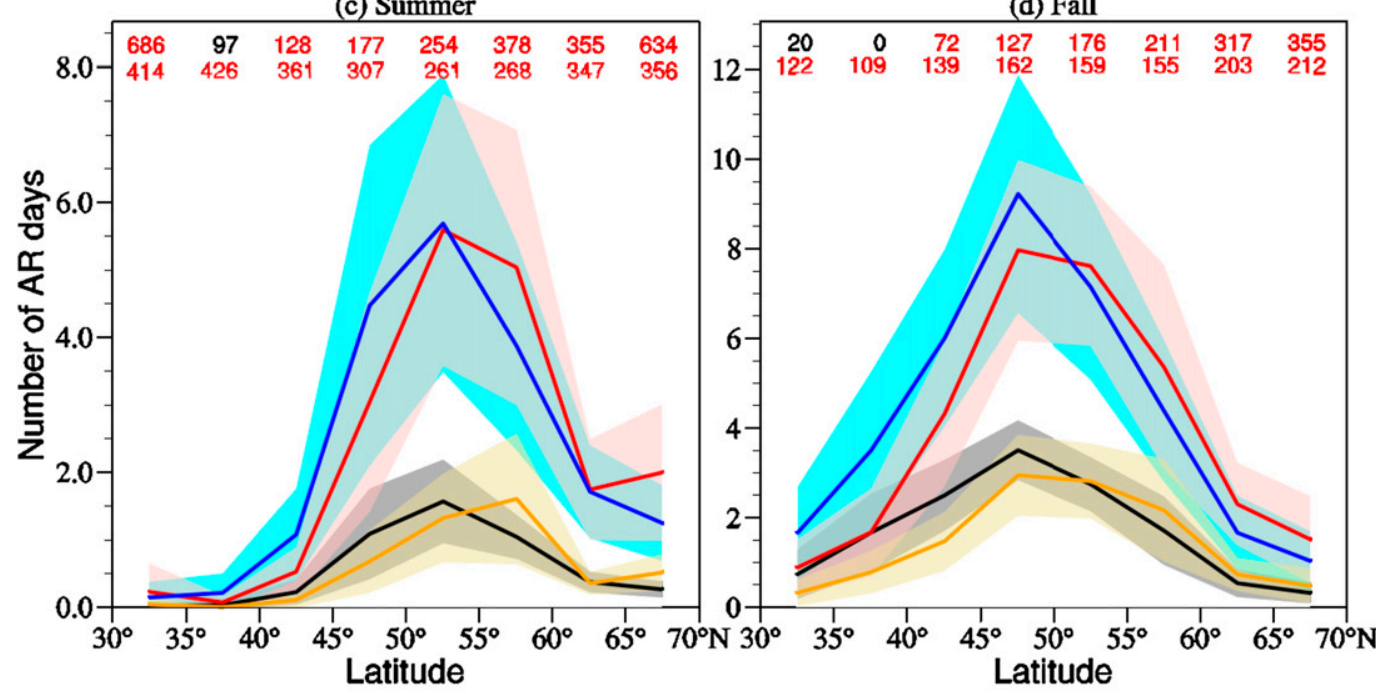

Present: $V_{1} Q_{1}$

RCP8.5: $V_{2} Q_{2}$

$V_{2} \bar{Q}_{1}$

$V_{1} \bar{Q}_{2}$

FIG. 4. The CMIP5 MME mean seasonal total numbers of AR days over eight latitudinal bins $\left(30^{\circ}-70^{\circ} \mathrm{N}\right)$ for present (1975-2004, black) and future climate conditions in RCP8.5 (2070-99, red). Also shown are the numbers of AR days from rescaling of the future IVT by the present IWV $\left(V_{2} \bar{Q}_{1}\right.$, orange $)$ and present IVT by future IWV $\left(V_{1} \bar{Q}_{2}\right.$, blue). The shaded areas represent one standard deviation of the CMIP5 intermodel spread. The numbers across the top in each panel indicate the percentage changes of AR, calculated based on $\left(V_{2} Q_{2}-V_{1} Q_{1}\right) / V_{1} Q_{1} \times$ $100 \%$ whereas the row of numbers below shows the thermodynamical effect calculated through $\left(V_{1} \bar{Q}_{2}-V_{1} Q_{1}\right) / V_{1}$ $Q_{1} \times 100 \%$, with the red numbers indicating statistical significance at the $95 \%$ level.

equatorward (poleward) bins for all four seasons, hinting at dynamical modulations on the future distribution of the ARs.

To elucidate the dynamical modulations on ARs, we rescale the future IVT by a factor of $q_{\mathrm{m} 2} / q_{\mathrm{m} 1}$, referred to as $V_{2} \bar{Q}_{1}$ (orange line in Fig. 4) and compare the AR days with those from $V_{1} Q_{1}$ (black line in Fig. 4). The resulting difference in AR days due to the wind change (or dynamical effects) is shown in Fig. 5 together with the corresponding changes in zonal wind. It is clear that the AR days increase and decrease following the changes in zonal wind speed averaged between the coast and $20^{\circ}$ westward for each $10^{\circ}$ latitudinal bin. A dipole pattern of positive and negative changes on each side of the peak AR frequency for the respective season (see the black curves in Fig. 5) indicates a poleward dynamical shift, in concert with the shift of the zonal wind. South of the peak area, the number of ARs is reduced dynamically due to the decreases in zonal wind speed, while north of the peak area the increases of zonal wind speed largely drive the increase of ARs. Alternatively, the change in AR days due to dynamical effects can be isolated by comparing the AR days detected for the present and 

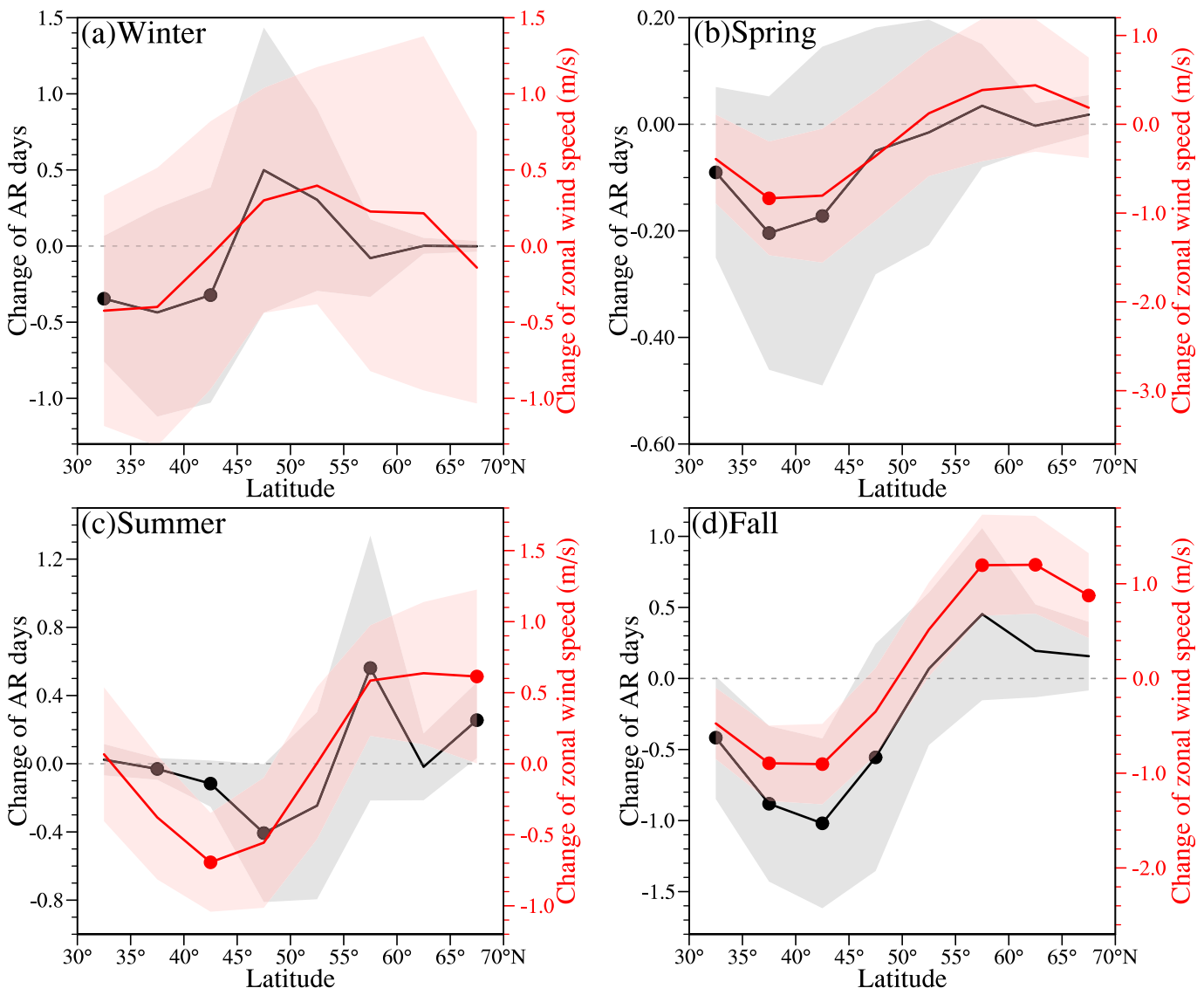

FIG. 5. Changes in the number of AR days due to dynamics (black curve), calculated using ARs detected with $V_{2} \bar{Q}_{1}$ (orange line in Fig. 4) minus that detected with $V_{1} Q_{1}$ (the black line in Fig. 4) as a function of latitude. Also shown are the changes of zonal wind speed (red curves, right $y$ axis), calculated by averaging the zonal wind speed for each $10^{\circ}$ latitudinal bin extending from the coast to $20^{\circ} \mathrm{W}$. The black and red dots indicate statistically significant changes for AR days and zonal winds, respectively, at the $95 \%$ level. Shading corresponds to one standard deviation above and below the CMIP5 MME mean.

future climate using their respective 85 th percentile IVT threshold. This is to eliminate the large influence of enhanced water vapor with warming that drives a significant increase in IVT. As discussed in Gao et al. (2015), this method circumvents the errors due to neglecting the covariance between water vapor and winds in the rescaling method. Overall, we found consistent changes in AR days due to dynamical effects using the rescaling method and the respective percentile IVT thresholds for present and future climate. The latter approach of isolating the dynamical effect is referred to as the "percentile scaling" method.

\section{c. Exploring an emergent constraint on AR changes in a warmer climate}

Recently, the idea of emergent constraint has been proposed to link a parameter of the current climate of a general circulation model to the response of the parameter in question to anthropogenic forcing [e.g.,
Zelinka et al. 2012; Klein et al. 2013; Qu et al. 2014; Sherwood et al. 2014); see the review of Klein and Hall (2015)]. To be qualified as an emergent constraint, three conditions have to be satisfied by the parameter: 1 ) there is correlation between the current and future climate parameters; 2) the relationship is physically justifiable; and 3) the parameter is observable and the model representation of the parameter is in error compared to the observations. The eddy-driven jet can potentially serve as a candidate of emergent constraint. For example, Kidston and Gerber (2010) found a statistically significant correlation between the equatorward model bias in the mean position of the Southern Hemisphere jet and the amount of the jet shift under increasing greenhouse gas forcing. This relationship may be explained by the greater eddy momentum feedback to the southern annular mode manifested in the jet response to external forcing when the jet is more equatorward biased (Barnes and Hartmann 2010b; Burrows et al. 2016, manuscript 


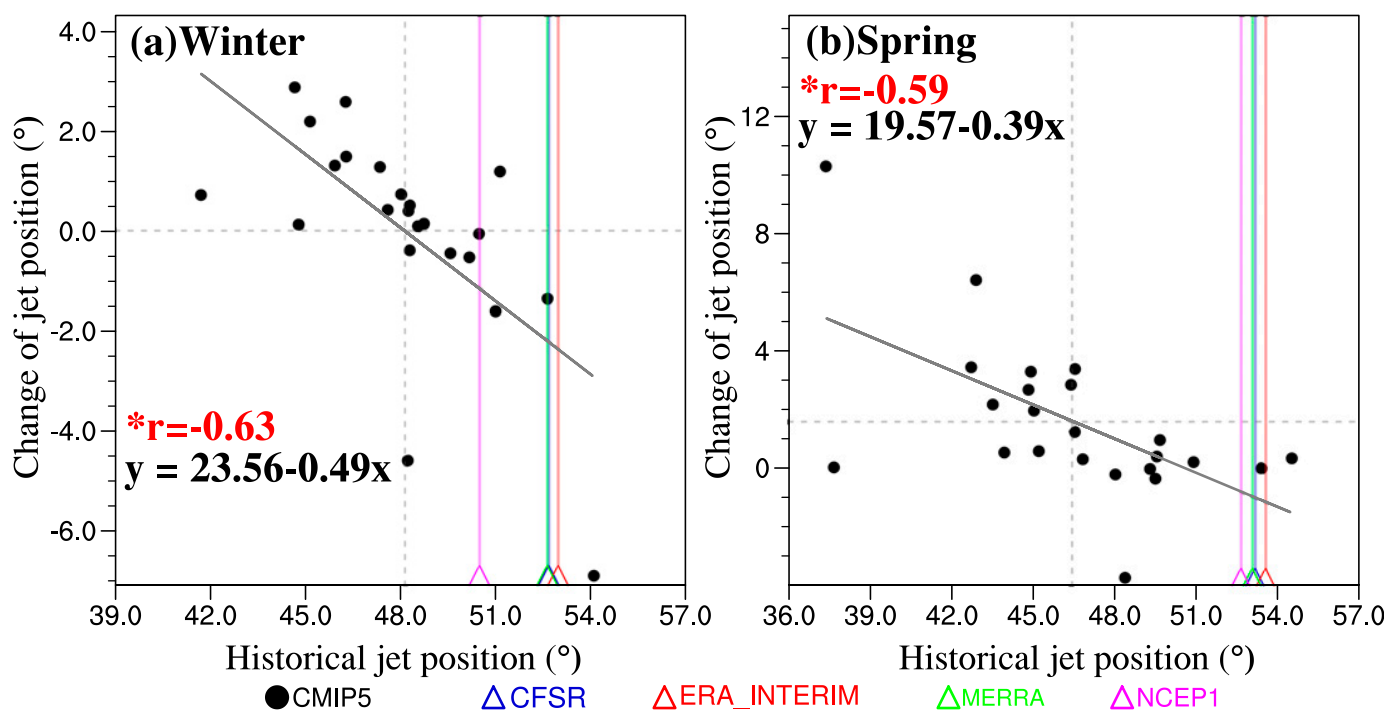

FIG. 6. Correlation between the CMIP5-model-simulated historical jet positions and projected changes of jet position in the future under RCP8.5 for (a) winter and (b) spring. The four colored triangles indicate the jet position from the four reanalysis datasets. The multimodel mean historical jet positions and changes of jet positions are indicated by the gray dashed lines. The expected changes of jet position from the four reanalysis datasets are the values at the intersections between the colored solid lines and the regression line.

submitted to J. Atmos. Sci.). To see if an emergent constraint is potentially present in the Atlantic westerly wind, we plot the shift of the Atlantic jet position (the latitude of the maximum of the seasonal mean $850-\mathrm{hPa}$ zonal wind averaged between $30^{\circ} \mathrm{W}$ and $10^{\circ} \mathrm{E}$, defined in section 3a) against its mean position for CMIP5 models for both the winter (Fig. 6a) and spring (Fig. 6b) seasons. Indeed, models with a larger equatorward bias in the historical jet position project a larger poleward shift in the future. This relationship is stronger in winter than spring. But unlike the robust poleward shift of the Southern Hemispheric jet stream (Kidston and Gerber 2010), there is considerable uncertainties in the sign of the projected shift of North Atlantic westerlies, with the CMIP5 MME mean shift close to zero in winter and about $1.5^{\circ}$ poleward in spring (gray horizontal dashed lines in Fig. 6). Were the latitudinal position of the jet used as an emergent constraint and the reanalysis as the observation, the projected CMIP5 MME mean shift of the jet would be calibrated to be about $2.0^{\circ}$ equatorward in winter and about $1^{\circ}$ equatorward in spring.

What would this possible emergent constraint entail in the projection of the future AR days? To answer this question, we examine the relationship for winter and spring, respectively, between the mean westerly position and the dynamical modulation on the changes in landfalling AR derived from the percentile scaling threshold method as explained in section $3 b$ (Fig. 7).

Although a shift of the westerly jet should steer the storm track toward the direction of the shift, the relationship between the jet shift and the change of the ARs might not be as straightforward. Recent studies suggested that ARs can be considered largely as a signature of moisture transport of anticyclonic Rossby wave breaking (AWB) at the equatorward flank of the mean jet (e.g., Payne and Magnusdottir 2014), whereas the relationship between the poleward shift of the jet stream and the distribution of wave breaking can be complicated and model dependent. Notwithstanding, both comprehensive climate models under increased greenhouse gas forcing (Rivière 2011; Barnes and Hartmann 2012) and idealized atmospheric general circulation model under a tropical heating mimicking the effect of increasing greenhouse gas (Lu et al. 2014b) indicate that the poleward shift of the eddy-driven jet under global warming accompanies a dipole in the occurrence of the AWB with a decrease (an increase) in frequency to the more equatorward (poleward) latitudes. On the other hand, the cyclonic wave breaking (CWB) change concomitant with the jet shift under global warming is more characterized by a reduction in frequency (see Fig. 9 in Lu et al. 2014b; Barnes and Hartmann 2012), and the relationship between the CWB and ARs are much more tenuous (Ryoo et al. 2015). Taken together, with the dipole in the nonwave-breaking moisture transport in the storm track, we anticipate a greater dynamically induced decrease of the $\mathrm{AR}$ frequency on the equatorward side of the mean jet, but not necessarily a greater increase on the poleward side, for a greater poleward shift under global warming scenarios. 

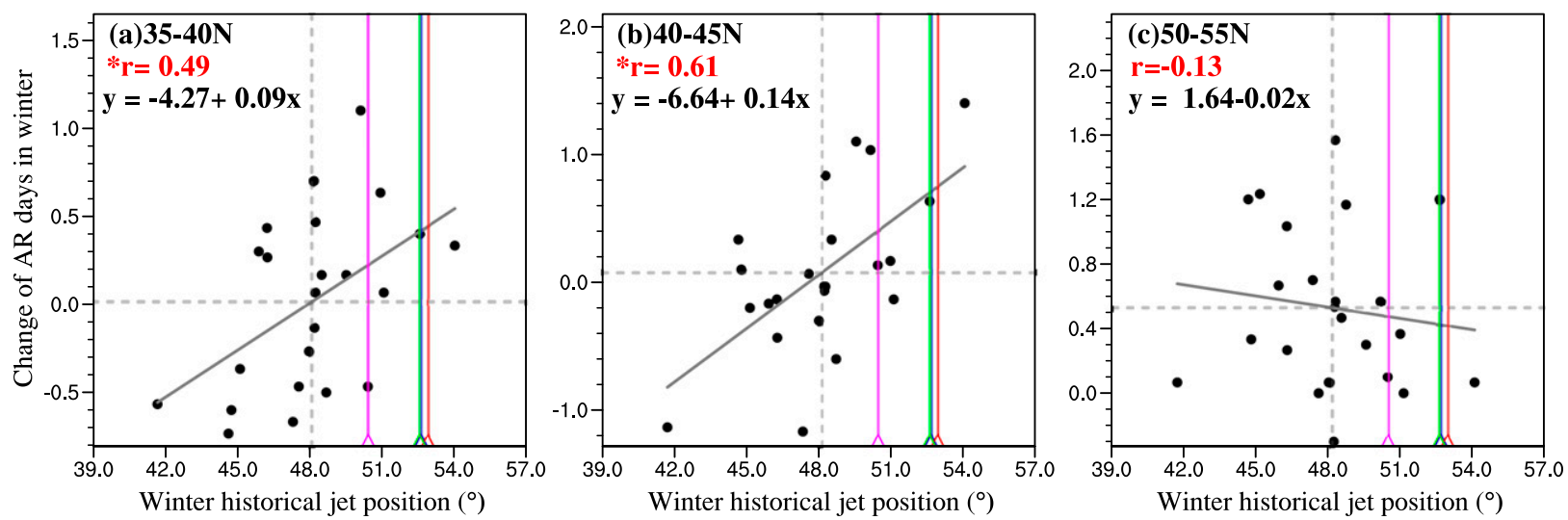

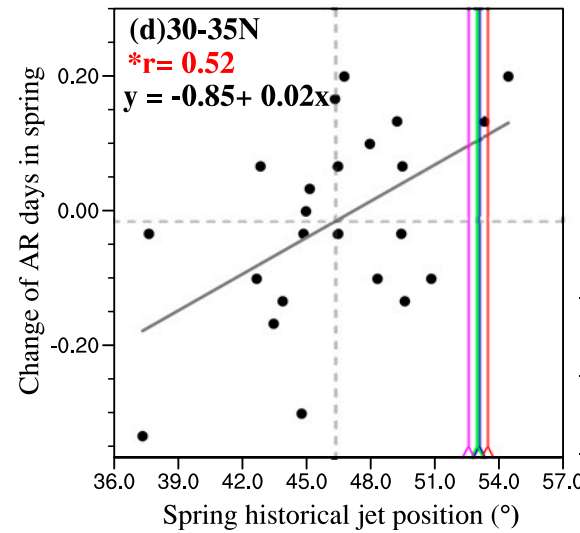

CMIP5

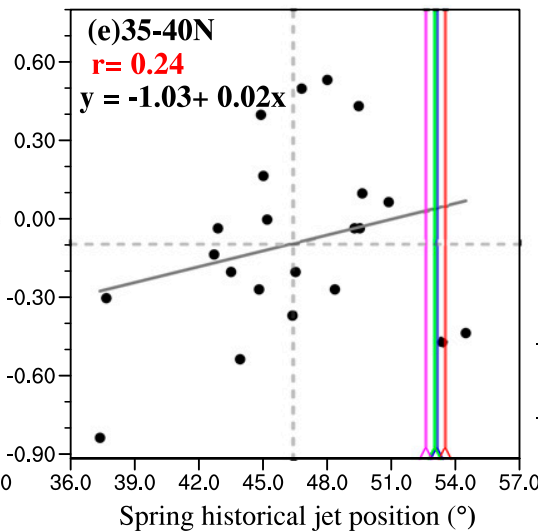

$\triangle E R A \_I N T E R I M$

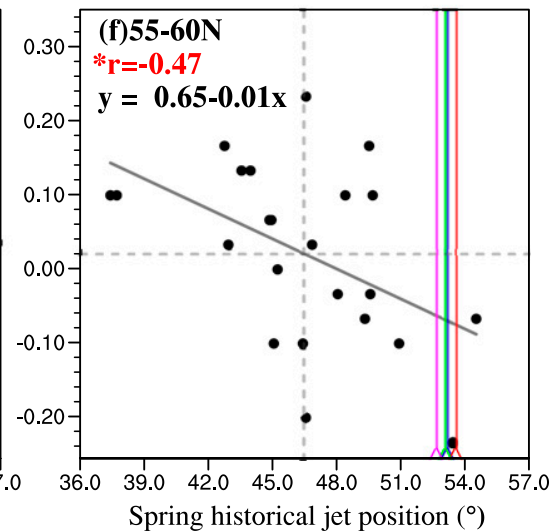

$\triangle$ NCEP1

FIG. 7. As in Fig. 6, but for correlation between the historical jet position and the changes of AR days due to dynamical effects in (a)(c) winter and (d)-(f) spring at three latitudinal regions. The multimodel mean historical jet positions and changes of AR days due to dynamical effects are indicated by the gray dashed lines.

Indeed, for both winter and spring we find significant positive correlations between the dynamical change of the ARs at the subtropical bins and the latitude of the historical jet position (Figs. 7a,d), likely a result of the greater poleward shift (illustrated in Fig. 6) of the more equatorward biased mean jet under the RCP8.5 forcing. Also as expected, these positive correlations transition to no or weak negative correlations for the latitudinal bins near and poleward of the mean jet (Figs. 7b,c,e,f). Note that the mean jet position during winter and spring is located around $45^{\circ}-50^{\circ} \mathrm{N}$, which coincides with the transition zone from the positive to the negative correlations. The CMIP5 MME mean change of AR days due to dynamical modulation during winter is close to zero for the two latitude bins $\left(35^{\circ}-45^{\circ} \mathrm{N}\right.$, near Portugal and the Spanish coast; Figs. $7 \mathrm{a}, \mathrm{b})$ where the correlations are both significant. Applying the emergent constraint by adjusting the MME mean projection of AR days along the gray regression slope toward the reanalysis position as the observational constraint (Figs. 7a,b), one would project the AR days to increase by an extra
0.4 days above the CMIP5 ensemble mean change for $35^{\circ}-40^{\circ} \mathrm{N}$ bin and 0.7 days for the $40^{\circ}-45^{\circ} \mathrm{N}$ bin in winter. This is consistent with the equatorward calibration of the projected Atlantic westerly wind shift as implied by the equatorward bias of the MME mean westerly position (Fig. 6a). Owing to the tenuous relationship between the jet shift and the ARs on the poleward side of the jet, we refrain from exercising the emergent constraint on the dynamical modulation of the AR frequency on the poleward side of the jet in spring, in spite of the apparent significant correlation shown in Fig. 7f.

\section{Changes of landfalling AR-induced precipitation in the future}

By virtue of the enhanced water vapor transport, heavy precipitation often accompanies landfalling ARs as they encounter mountainous terrains that provide a lifting mechanism for cloud formation. We define AR-induced precipitation as the precipitation over land that occurs on the same day as the AR and one day after the AR (Rutz and Steenburgh 2012) and within $250 \mathrm{~km}$ of 

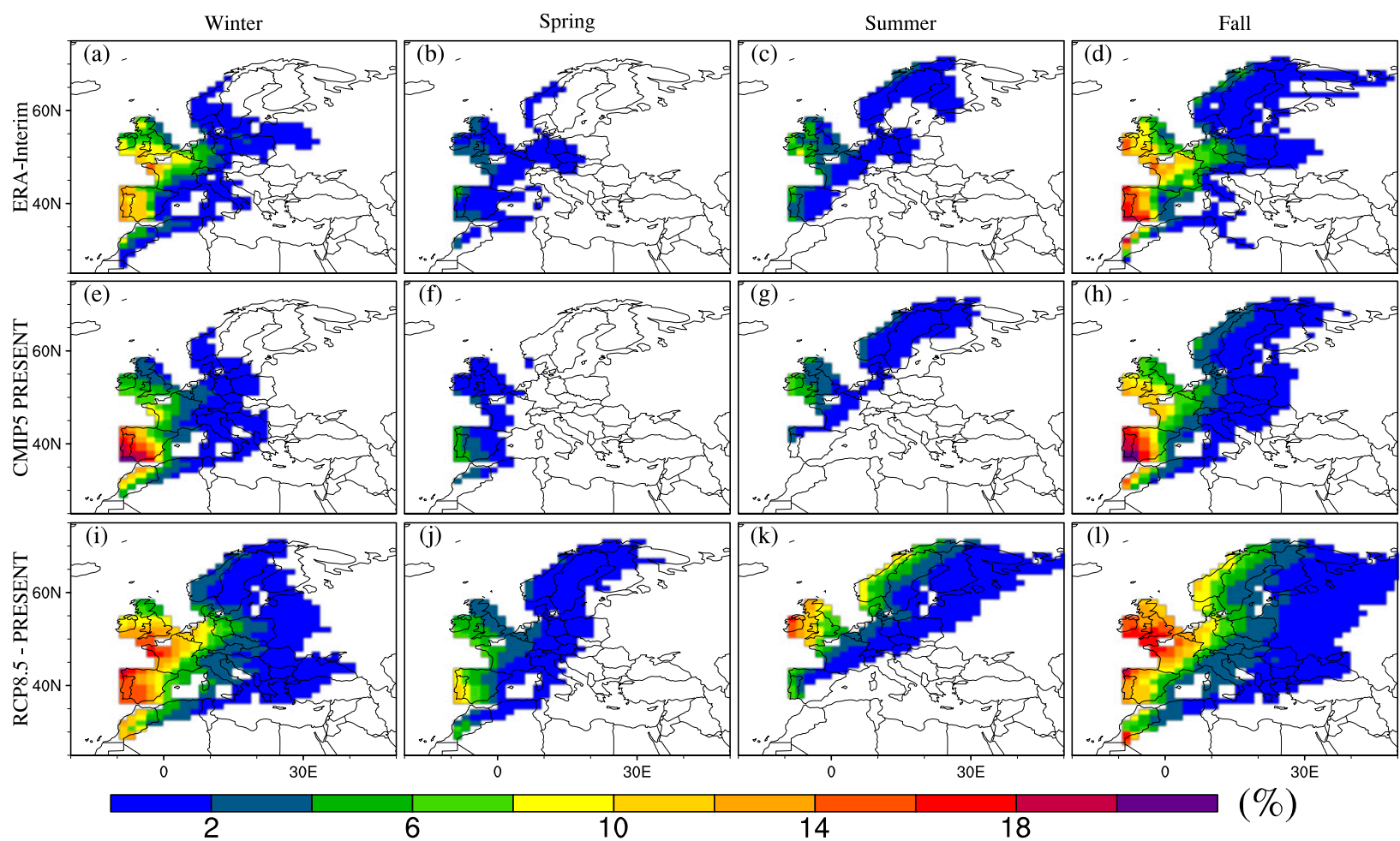

FIG. 8. The fractional contribution of AR-induced precipitation to the total precipitation in each season from (a)-(d) ERA-Interim (1979-2004) and (e)-(h) CMIP5 MME at present (1975-2004), and (i)-(l) the difference between CMIP5 MME in RCP8.5 and present (2070-99 minus 1975-2004).

the AR trajectory defined in section 2. The AR-induced precipitation is considered extreme if the daily precipitation amount exceeds the 95th percentile of all daily precipitation greater or equal to $1 \mathrm{~mm}$ in each season. The fractional contributions of AR-induced precipitation to the seasonal total precipitation are shown in Fig. 8, with the ERA-Interim in the top row and present and future CMIP5 MME mean in the middle and bottom rows. Similar fractional contributions but for AR-induced total seasonal extreme precipitation are shown in Fig. 9. Only grids with at least 70\% of CMIP5 models producing AR-induced precipitation are shown in Figs. 8-11. The percentage changes (Figs. 8-11) are calculated based on the CMIP5 MME mean AR precipitation and IVT as their changes. The global ERA-Interim (Figs. 8a-d) shows the largest AR contribution (up to $10 \%-20 \%$ ) to precipitation occurs in winter and fall along the coast line following the topography, including the Iberian Peninsula (Portugal and Spain), northern France (north of Pyrenees), southern Benelux, western Great Britain, and Norway (west of the Scandinavian mountains). Similar seasonal and spatial patterns (Figs. 9a-d) are noted for the AR contributions to seasonal extreme precipitation, except that the latter more than doubles the AR contributions to seasonal total precipitation, because ARs are sporadic events with the potential to generate intense precipitation. This orographic feature was also noted in Lavers and Villarini (2013), who found that AR accounts for a large portion of annual maximal precipitation in Europe with the largest contribution of $40 \%$ or more, which is comparable to the AR contributions (highest contributions reaching $45 \%$ or more) to extreme precipitation found in this study (Figs. 9a-d). Overall, the CMIP5 MME captures the spatial variability of the AR contributions to seasonal total and extreme precipitation (Figs. 8a-h and 9a-h), albeit with a slight overestimation from $35^{\circ}$ to $45^{\circ} \mathrm{N}$ in fall and winter. The overestimation is primarily contributed by the positive bias in the number of ARs in CMIP5 as discussed in section 3a. Note that our estimates of AR contributions are slightly lower than those of Lavers and Villarini (2015) because a smaller IVT threshold of 50th percentile (ranges from 218 to $295 \mathrm{~kg} \mathrm{~m}^{-1} \mathrm{~s}^{-1}$ with an average of $244 \mathrm{~kg} \mathrm{~m}^{-1} \mathrm{~s}^{-1}$ ) was used in that study, which is on average $38 \%$ lower than the threshold used in this study as shown in Table S2.

Under climate warming, the contributions of ARinduced precipitation to both the seasonal total and extreme precipitation increase substantially. For instance, the contributions of AR-induced precipitation to 

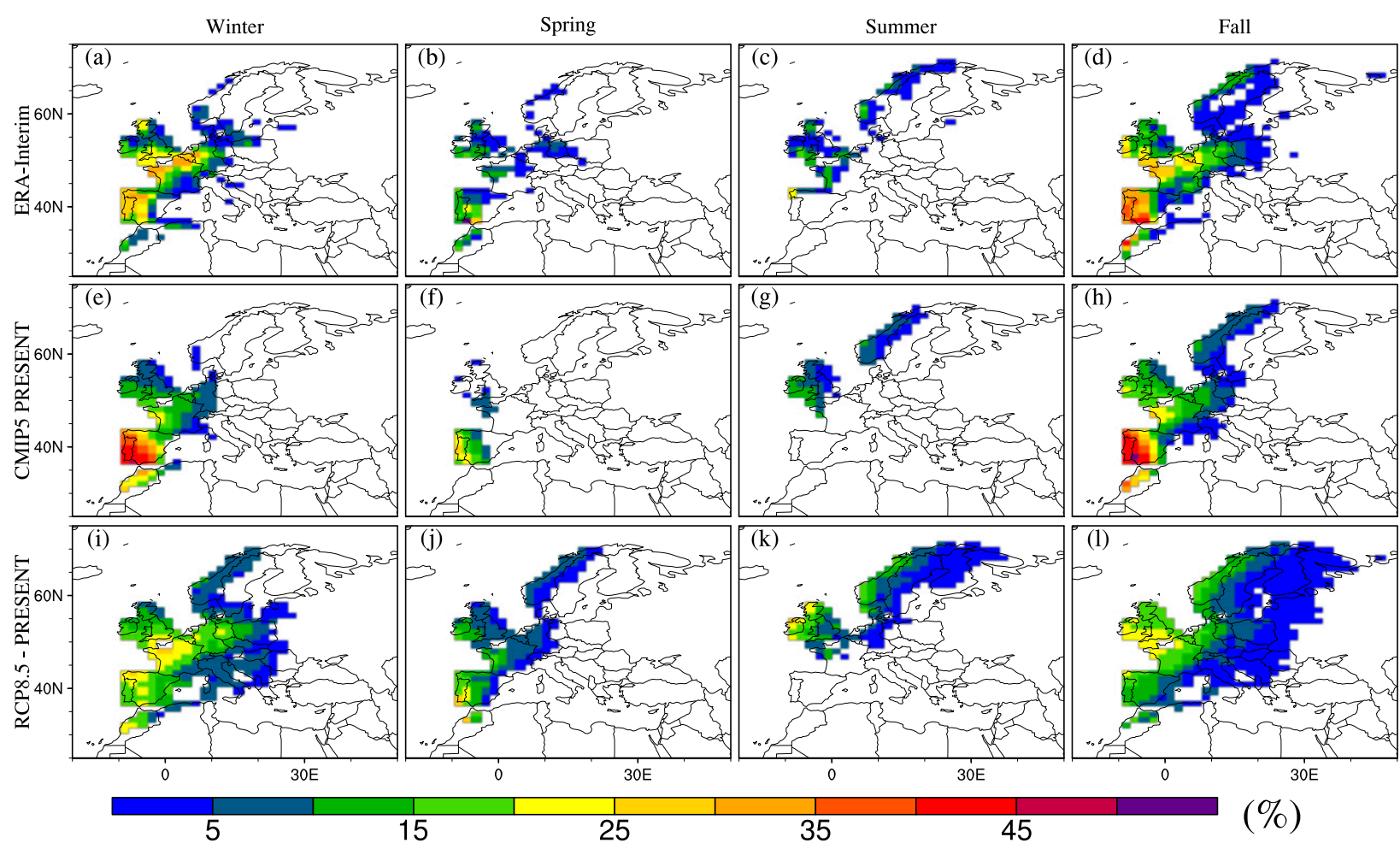

FIG. 9. As in Fig. 8, but for extreme precipitation.

the total precipitation are projected to increase by $10 \%-$ $20 \%$ (Figs. $8 \mathrm{i}-1$ ) from $35^{\circ}$ to $55^{\circ} \mathrm{N}$ along the coastal areas, with the largest increase in winter (Fig. 8a) and fall (Fig. 8d), including the Iberian Peninsula (Portugal and Spain), Ireland and the United Kingdom, northern France, southern Benelux, and part of Germany, with more modest increase projected for other areas and seasons (i.e., spring and summer). Similar increases $(15 \%-$ $25 \%$ ) in the contributions of ARs to extreme precipitation are found in the west coast of Europe from $35^{\circ}$ to $55^{\circ} \mathrm{N}$, and as a result ARs are projected to contribute to $25 \%-70 \%$ of seasonal extreme precipitation in the future.

The total precipitation and extreme precipitation in the future is generally projected to increase in Europe by $20 \%-80 \%$ (Scoccimarro et al. 2015), so the increase of AR contribution to both total and extreme precipitation in the future indicates that AR-induced precipitation increases at a higher percentage compared to increases in total precipitation. To further understand the changes in AR precipitation, Fig. 10 shows the percentage changes in AR total and extreme precipitation and the corresponding changes in IVT for winter. Lavers et al. (2014) showed that in Europe, AR-induced precipitation is highly correlated with the IVT, particularly in mountainous regions where moisture flux convergence from orographic uplift is quasi-stationary. In particular, IVT may be a useful proxy for moisture flux convergence upwind of mountains. Hence a comparison between the changes in precipitation and IVT may provide some insights into potential changes in ARrelated precipitation processes in a warmer climate. Most areas in Europe are marked by large percentage increases in total precipitation of above $100 \%$ (Fig. 10a). The changes are particularly significant in central Europe near $50^{\circ} \mathrm{N}$. Changes in IVT (Fig. 10c) generally follow a similar spatial pattern. Compared to the changes in AR total precipitation (Fig. 10a), the increases in AR extreme precipitation (Fig. 10b) are generally smaller, and comparable to the changes in AR extreme IVT as well (Fig. 10d).

To delineate the contributions to changes in AR precipitation from changes in AR precipitation frequency versus precipitation intensity, Fig. 11 shows the same changes corresponding to Fig. 10, but with the precipitation and IVT normalized by the AR days, hence representing the changes in intensity rather than the total amount. For all the quantities shown in the Fig. 11, the percentage changes in intensity are much smaller than that of the total amount, demonstrating that the significant increases shown in Fig. 10 as well as the increased contributions of ARs to total and extreme precipitation shown in Figs. 8 and 9 are largely associated with the increases in AR days in the future. Comparing the intensity changes in AR 

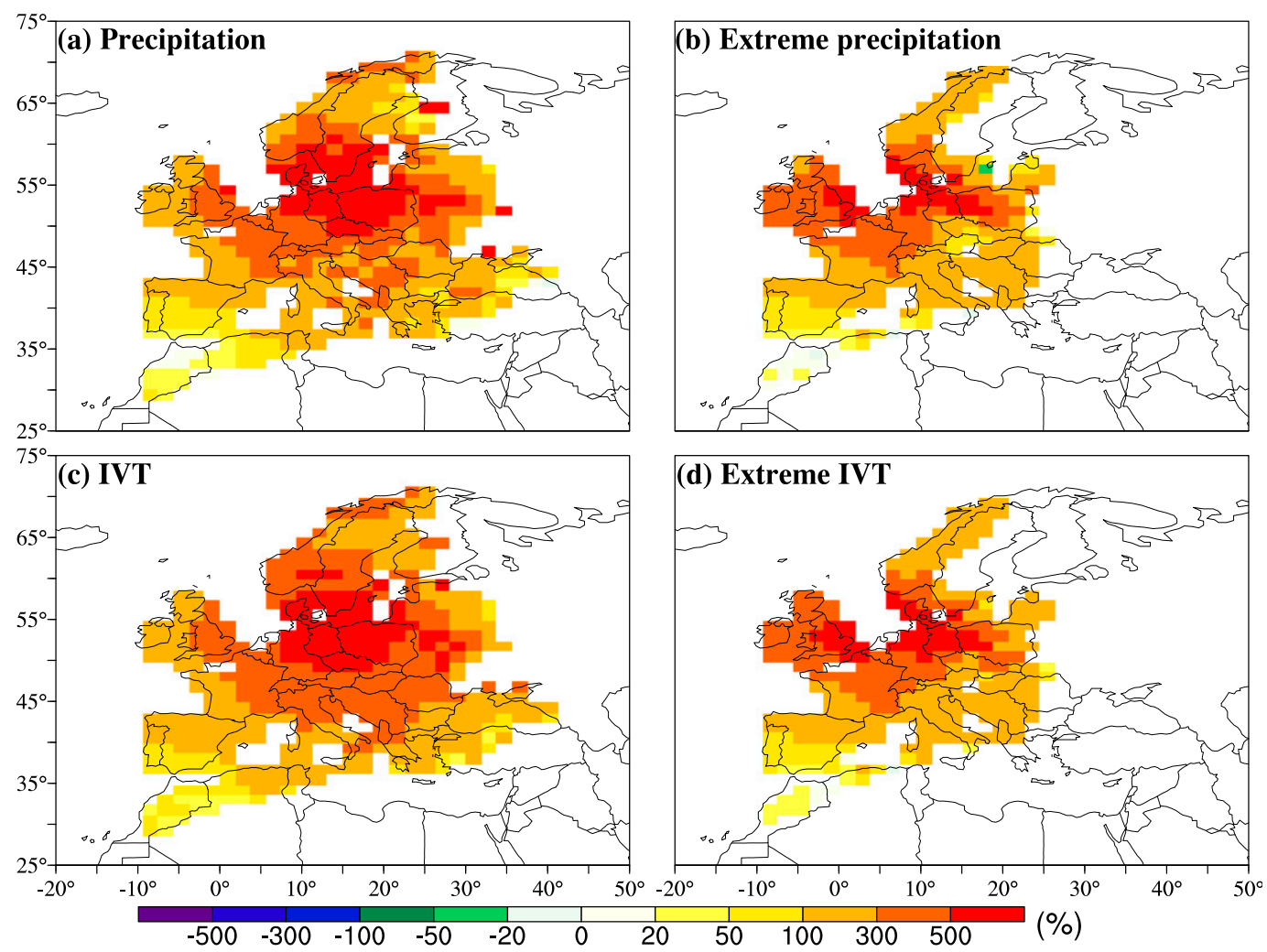

FIG. 10. Percentage change in winter AR (a) total precipitation, (b) extreme precipitation, (c) total IVT, and (d) extreme IVT from the CMIP5 MME comparing the present (1975-2004) with the future (2070-99).

precipitation (Fig. 11a) and IVT (Fig. 11c), decreases in AR precipitation intensity (Fig. 11a) are notable in Portugal, Spain, Morocco, and part of northern Europe, despite increases in IVT intensity corresponding to warming in the future. Similar results are also obtained for the fall season when ARs also occur frequently.

Comparing the percentage changes in AR total (Fig. 11a) and extreme (Fig. 11b) precipitation intensity, changes in the latter are generally much smaller. An even more striking difference between the two is that while AR total precipitation intensity (Fig. 11a) is comparable or amplified in central Europe compared to the IVT (Fig. 11c) changes, the increases in AR extreme precipitation (Fig. 11b) intensity are overall subdued compared to the extreme IVT (Fig. 11d) changes. In Portugal, Spain, and France, AR extreme precipitation intensity (Fig. 11b) increases by less than $8 \%$ compared to increases of up to $20 \%$ in the extreme IVT (Fig. 11d). In the Scandinavian mountains and the Alps, AR extreme precipitation intensity (Fig. 11b) decreases by a few percent compared to increases in AR extreme IVT by up to $50 \%$. This suggests potentially different processes governing changes in AR total and extreme precipitation in a warmer climate.

\section{Discussion and conclusions}

This study investigates the landfalling atmospheric rivers over western Europe in the present and future climate. The CMIP5 models reasonably capture the seasonal and spatial distributions of AR days. Although the CMIP5 MME mean AR days are generally comparable to those determined from four global reanalysis products, there are significant intermodel spreads, indicating large uncertainties in simulating AR days by state-of-the-art global climate models. Analysis of the atmospheric circulation demonstrates statistically significant correlations of model biases and uncertainties in simulating AR days with those of the jet position and strength simulated by the models. As most CMIP5 models show an equatorward jet bias, more AR events are simulated south of the mean jet position $\left(45^{\circ}-55^{\circ} \mathrm{N}\right)$ by the CMIP5 models than the reanalyses and vice versa for the poleward side of the jet.

A poleward shift of the annual mean jet position in a warmer climate has been identified in several generations of coupled climate simulations (Yin 2005; Miller et al. 2006; Kidston and Gerber 2010; Swart and Fyfe 2012; Barnes and Polvani 2013). Despite the rather robust tendency for the poleward shift, models disagree on 

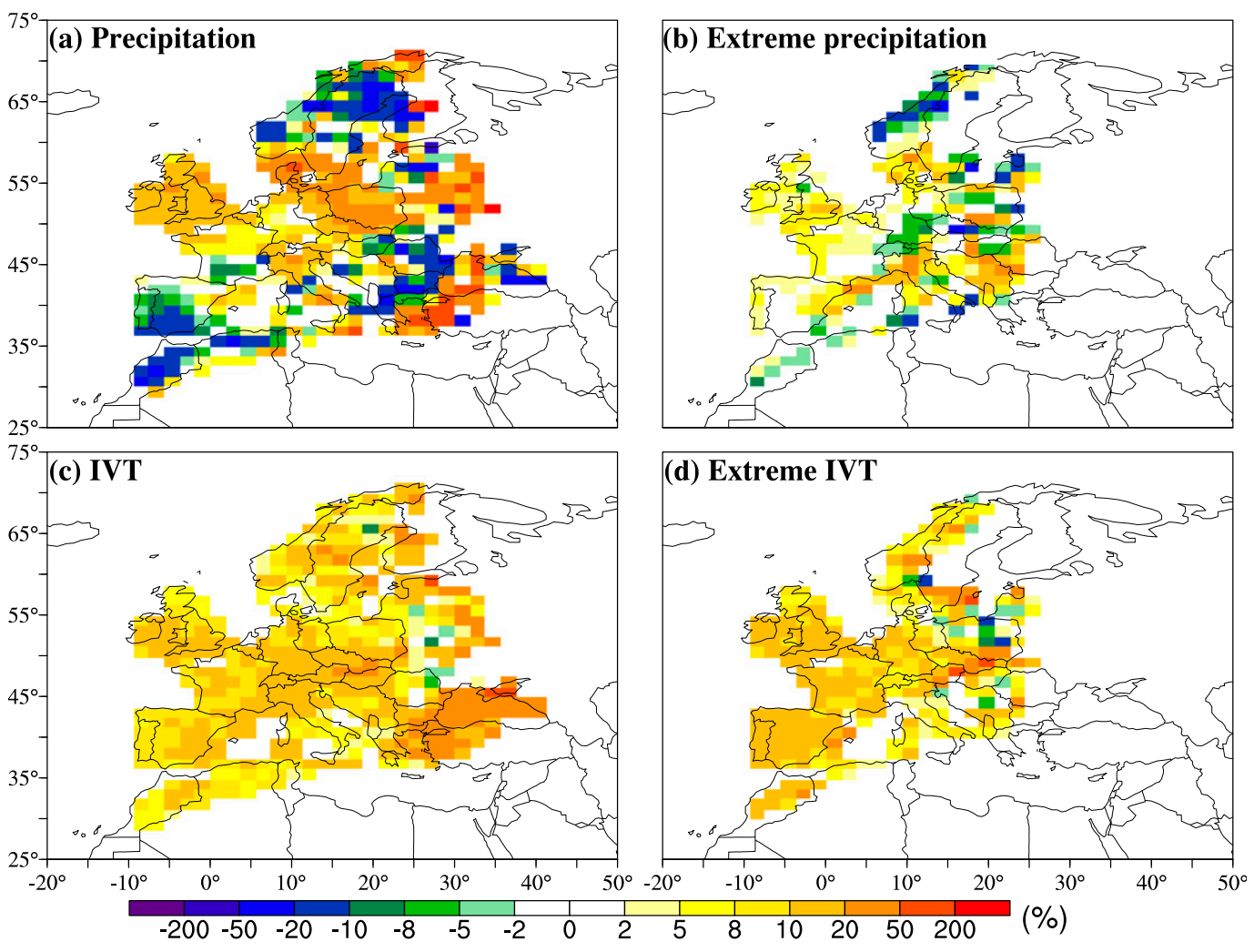

FIG. 11. As in Fig. 10, but for intensity of AR.

the extent of the poleward shift and the eastward extension of the jet that results in large uncertainty in projecting regional precipitation changes in the extratropics (Neelin et al. 2013; Langenbrunner et al. 2015). The dependence of ARs on the jet stream has been demonstrated for ARs in aquaplanet simulations (Hagos et al. 2015) and ARs making landfall in western North America (Gao et al. 2015; Hagos et al. 2016). Analysis in this study for ARs making landfall in western Europe provides further evidence of the relationships between AR frequency and jet position and speed. Thus, uncertainty in projecting the changes in jet stream may also project onto uncertainty in projecting changes in ARs.

By the end of this century, the number of AR events in western Europe was projected to increase by a few times $(127 \%-275 \%$ increase at peak AR frequency regions: $\left.45^{\circ}-55^{\circ} \mathrm{N}\right)$ compared to the historical level. Through a rescaling method, we found that thermodynamical changes play a dominant role in the future increase of ARs, but dynamical effects, mainly reflected through the wind changes, play a significant role as well. The changes in AR days due to dynamical changes show a dipole feature with an overall negative (positive) effect south (north) of the CMIP5 MME mean jet position. This dipole feature aligns well with the changes in zonal wind speed and consistent with the poleward jet shifts projected by the CMIP5 models.

Previous studies have identified significant correlations between the model-projected shifts in the midlatitude jet positions with the simulated climatological jet position in the Southern Hemisphere (Kidston and Gerber 2010; Grise and Polvani 2014). In the North Atlantic, we found similar correlations for winter and spring. With the overall equatorward bias in the jet position in CMIP5, the projected future jet positions are predominantly poleward shifted. Recognizing the relationships between the jet positions and ARs occurring in the subtropics, we explored the use of the historical jet positions as emergent constraints on the projection of AR days in the future and found statistically significant correlations between the two. Accounting for the equatorward jet bias in CMIP5 climatology compared with the global reanalyses, for models with greater equatorward biases, the projected change of winter AR days due to dynamics should be adjusted upward for the European coast within the subtropical latitude range, in addition to the large increase associated with water vapor increases in the future.

For an emergent constraint to be effective, the empirical relationship between intermodel variations of an observable quantity and the intermodel variations in a 
future climate prediction must have a physical explanation (Klein and Hall 2015). The dynamical basis for the historical jet position as an emergent constraint for AR changes consists of two relationships linking the historical jet position with the projected jet shift, and the projected jet shift with the projected AR frequency changes. Barnes and Hartmann (2010b) found that when the Atlantic jet is more equatorward during the negative phase of the North Atlantic Oscillation (NAO), positive eddy feedback due to the enhanced baroclinicity and anomalous northward eddy propagation away from the jet helps maintain the jet in an equatorward position and a persistent negative NAO. Consistent with the above finding, Barnes and Hartmann (2010a) and Barnes and Polvani (2013) found that jet variability decreases as the mean jet is located more poleward. Hence the eddy feedback mechanism may also explain the overpersistence of the equatorward biased jet simulated by the CMIP5 models (Gerber et al. 2008), and hence their possible exaggeration of the poleward shift in response to external forcing (Kidston and Gerber 2010; Barnes and Polvani 2013). For the second relationship, ARs are often related to the anticyclonic Rossby wave breaking, which itself is associated with a strong equatorward wave activity propagation and poleward shift of the eddy-driven jet. The poleward jet shift under global warming has been linked to a dipole in the AWB frequency at the equatorward side of the mean jet (Rivière 2011; Lu et al. 2014b) and this might underlie the emergent relationship between the projected dynamical changes in the AR landfalling days at the subtropical coast of western Europe and the model biases in the mean jet position. Meanwhile, the possible connection among the CWB, the jet shift, and ARs remains unclear and warrants further investigation (e.g., Ryoo et al. 2015). Given the relationships between ARs and jet stream, improvements in simulating the jet position and strength may lead to improvements in simulating the number of ARs and reduce uncertainties in projecting AR changes in the future. Meanwhile, the emergent constraint identified in this study is important for understanding the uncertainty of and constraining the projections for AR changes. This is particularly relevant given some large biases in simulating nearsurface winds in the CMIP5 models revealed in Fig. 3.

Primarily because of the more abundant moisture but also because of the poleward jet shift that increases the wind speeds in the higher latitudes, ARs contribute more importantly to both total and extreme precipitation in western Europe in the future. However, changes in AR total and extreme precipitation intensity reveal smaller increases (or even decreases) compared to the amount, suggesting that the increased contributions from AR are mainly a result of increased AR frequency in a warmer climate. Generally, the increase in AR total precipitation intensity in central Europe is comparable to the IVT changes, but much weaker (even decreases) in southern and northern Europe.

AR extreme precipitation intensity generally decreases compared to the AR extreme IVT intensity. Previous studies found that extreme precipitation in the extratropics scales approximately with thermodynamics following the Clausius-Clapeyron (C-C) relationship as the dynamical effects from changes in vertical velocity are small (Emori and Brown 2005; O'Gorman and Schneider 2009), except potentially for regions influenced by the poleward jet shift (O'Gorman and Schneider 2009; Lu et al. 2014a). For nonconvective events in the extratropics, O'Gorman (2015) further showed weak dependence of extreme precipitation on changes in static stability. With dynamical influence potentially limited, possible reasons for reduction in AR extreme precipitation intensity include changes in microphysical processes related to freezing level and hydrometeor fall speed (Singh and O'Gorman 2014) and changes in orographic precipitation, with precipitation shifted downwind, reducing the total precipitation compared to the C-C scaling (Siler and Roe 2014). The latter may be particularly relevant for the negative changes in AR extreme precipitation in the Scandinavian mountains and the Alps. However the simulated changes reported here may be hampered by the relatively coarse spatial resolution and uncertainties in cloud parameterizations in the CMIP5 models, so further investigations are warranted to understand the dynamical, thermodynamical, and microphysical factors that modulate the AR extreme precipitation response to warming. As model resolution increases with advances in computational resources, potential improvements in simulating the jet stream (Lu et al. 2015) and orographic effects may improve understanding and lead to more reliable projections of future changes in AR days and extreme precipitation.

Acknowledgments. This study was supported by the U.S. Department of Energy Office of Science Biological and Environmental Research (BER) as part of the Regional and Global Climate Modeling program (KP1703010). PNNL is operated for DOE by Battelle Memorial Institute under Contract DE-AC0576RL01830. We acknowledge the World Climate Research Programme's Working Group on Coupled Modelling, which is responsible for CMIP, and we thank the climate modeling groups for producing and making available their model output. 


\section{REFERENCES}

Barnes, E. A., and D. L. Hartmann, 2010a: Influence of eddydriven jet latitude on North Atlantic jet persistence and blocking frequency in CMIP3 integrations. Geophys. Res. Lett., 37, L23802, doi:10.1029/2010GL045700.

_ , and $-2010 \mathrm{~b}$ : Dynamical feedbacks and the persistence of the NAO. J. Atmos. Sci., 67, 851-865, doi:10.1175/ 2009JAS3193.1.

— , and —_, 2012: Detection of Rossby wave breaking and its response to shifts of the midlatitude jet with climate change. J. Geophys. Res., 117, D09117, doi:10.1029/2012JD017469.

— , and L. Polvani, 2013: Response of the midlatitude jets, and of their variability, to increased greenhouse gases in the CMIP5 models. J. Climate, 26, 7117-7135, doi:10.1175/JCLI-D-12-00536.1.

Dee, D. P., and Coauthors, 2011: The ERA-Interim reanalysis: Configuration and performance of the data assimilation system. Quart. J. Roy. Meteor. Soc., 137, 553-597, doi:10.1002/ qj. 828 .

Emori, S., and S. J. Brown, 2005: Dynamic and thermodynamic changes in mean and extreme precipitation under changed climate. Geophys. Res. Lett., 32, L17706, doi:10.1029/ 2005GL023272.

Gao, Y., J. Lu, L. R. Leung, Q. Yang, S. Hagos, and Y. Qian, 2015: Dynamical and thermodynamical modulations on future changes of landfalling atmospheric rivers over western North America. Geophys. Res. Lett., 42, 7179-7186, doi:10.1002/ 2015 GL065435.

Gerber, E. P., L. M. Polvani, and D. Ancukiewicz, 2008: Annular mode time scales in the Intergovernmental Panel on Climate Change Fourth Assessment Report models. Geophys. Res. Lett., 35, L22707, doi:10.1029/2008GL035712.

Grise, K. M., and L. M. Polvani, 2014: Is climate sensitivity related to dynamical sensitivity? A Southern Hemisphere perspective. Geophys. Res. Lett., 41, 534-540, doi:10.1002/2013GL058466.

Hagos, S. M., L. R. Leung, Q. Yang, C. Zhao, and J. Lu, 2015: Resolution and dynamical core dependence of atmospheric river frequency in global model simulations. J. Climate, $\mathbf{2 8}$, 2764-2776, doi:10.1175/JCLI-D-14-00567.1.

,-- J.-H. Yoon, J. Lu, and Y. Gao, 2016: A projection of changes in landfalling atmospheric river frequency and extreme precipitation over western North America from the Large Ensemble CESM simulations. Geophys. Res. Lett., 43, 1357-1363, doi:10.1002/2015GL067392.

Kalnay, E., and Coauthors, 1996: The NCEP/NCAR 40-Year Reanalysis Project. Bull. Amer. Meteor. Soc., 77, 437-471, doi:10.1175/1520-0477(1996)077<0437:TNYRP>2.0.CO;2.

Kidston, J., and E. P. Gerber, 2010: Intermodel variability of the poleward shift of the austral jet stream in the CMIP3 integrations linked to biases in 20th century climatology. Geophys. Res. Lett., 37, L09708, doi:10.1029/2010GL042873.

Klein, S. A., and A. Hall, 2015: Emergent constraints for cloud feedbacks. Curr. Climate Change Rep., 1, 276-287, doi:10.1007/s40641-015-0027-1.

—, Y. Zhang, M. D. Zelinka, R. Pincus, J. Boyle, and P. J. Gleckler, 2013: Are climate model simulations of clouds improving? An evaluation using the ISCCP simulator. J. Geophys. Res. Atmos., 118, 1329-1342, doi:10.1002/jgrd.50141.

Langenbrunner, B., J. D. Neelin, B. R. Lintner, and B. T Anderson, 2015: Patterns of precipitation change and climatological uncertainty among CMIP5 models, with a focus on the midlatitude Pacific storm track. J. Climate, 28, 7857-7872, doi:10.1175/JCLI-D-14-00800.1.
Lavers, D. A., and G. Villarini, 2013: The nexus between atmospheric rivers and extreme precipitation across Europe. Geophys. Res. Lett., 40, 3259-3264, doi:10.1002/grl.50636.

, and - 2015: The contribution of atmospheric rivers to precipitation in Europe and the United States. J. Hydrol., 522, 382-390, doi:10.1016/j.jhydrol.2014.12.010.

, - _ R. P. Allan, E. F. Wood, and A. J. Wade, 2012: The detection of atmospheric rivers in atmospheric reanalyses and their links to British winter floods and the large-scale climatic circulation. J. Geophys. Res., 117, D20106, doi:10.1029/2012JD018027. , R. P. Allan, G. Villarini, B. Lloyd-Hughes, D. J. Brayshaw, and A. J. Wade, 2013: Future changes in atmospheric rivers and their implications for winter flooding in Britain. Environ. Res. Lett., 8, 034010, doi:10.1088/1748-9326/8/3/034010.

_ F. Pappenberger, and E. Zsoter, 2014: Extending mediumrange predictability of extreme hydrological events in Europe. Nat. Commun., 5, 5382, doi:10.1038/ncomms6382.

Leung, L. R., and Y. Qian, 2009: Atmospheric rivers induced heavy precipitation and flooding in the western U.S. simulated by the WRF regional climate model. Geophys. Res. Lett., 36, L03820, doi:10.1029/2008GL036445.

Lu, J., L. R. Leung, Q. Yang, G. Chen, W. D. Collins, F. Li, Z. J. Hou, and X. Feng, 2014a: The robust dynamical contribution to precipitation extremes in idealized warming simulations across model resolutions. Geophys. Res. Lett., 41, 2971-2978, doi:10.1002/2014GL059532.

_ L. Lun, Y. Wu, and G. Chen, 2014b: The role of subtropical irreversible PV mixing in the zonal mean circulation response to global warming-like thermal forcing. J. Climate, 27, 22972316, doi:10.1175/JCLI-D-13-00372.1.

, G. Chen, L. R. Leung, D. A. Burrows, Q. Yang, K. Sakaguchi, and S. Hagos, 2015: Toward the dynamical convergence on the jet stream in aquaplanet AGCMs. J. Climate, 28, 6763-6782, doi:10.1175/JCLI-D-14-00761.1.

Miller, R. L., G. A. Schmidt, and D. T. Shindell, 2006: Forced annular variations in the 20th century Intergovernmental Panel on Climate Change Fourth Assessment Report models. J. Geophys. Res., 111, D18101, doi:10.1029/2005JD006323.

Moss, R. H., and Coauthors, 2010: The next generation of scenarios for climate change research and assessment. Nature, 463, 747756, doi:10.1038/nature 08823 .

Neelin, J. D., B. Langenbrunner, J. E. Meyerson, A. Hall, and N. Berg, 2013: California winter precipitation change under global warming in the Coupled Model Intercomparison Project phase 5 ensemble. J. Climate, 26, 6238-6256, doi:10.1175/ JCLI-D-12-00514.1.

Neiman, P. J., F. M. Ralph, G. A. Wick, J. D. Lundquist, and M. D. Dettinger, 2008: Meteorological characteristics and overland precipitation impacts of atmospheric rivers affecting the west coast of North America based on eight years of SSM/I satellite observations. J. Hydrometeor., 9, 22-47, doi:10.1175/ 2007JHM855.1.

, L. J. Schick, F. M. Ralph, M. Hughes, and G. A. Wick, 2011: Flooding in western Washington: The connection to atmospheric rivers. J. Hydrometeor., 12, 1337-1358, doi:10.1175/ 2011JHM1358.1.

O'Gorman, P. A., 2015: Precipitation extremes under climate change. Curr. Climate Change Rep., 1, 49-59, doi:10.1007/ s40641-015-0009-3.

, and T. Schneider, 2009: The physical basis for increases in precipitation extremes in simulations of 21st-century climate change. Proc. Natl. Acad. Sci. USA, 106, 14773-14777, doi:10.1073/pnas.0907610106. 
Payne, A. E., and G. Magnusdottir, 2014: Dynamics of landfalling atmospheric rivers over the North Pacific in 30 years of MERRA reanalysis. J. Climate, 27, 7133-7150, doi:10.1175/ JCLI-D-14-00034.1.

- and - 2015: An evaluation of atmospheric rivers over the North Pacific in CMIP5 and their response to warming under RCP 8.5. J. Geophys. Res. Atmos., 120, 11173-11190, doi:10.1002/2015JD023586.

Qu, X., A. Hall, S. A. Klein, and P. M. Caldwell, 2014: On the spread of changes in marine low cloud cover in climate model simulations of the 21st century. Climate Dyn., 42, 2603-2626, doi:10.1007/s00382-013-1945-z.

Ralph, F. M., and M. D. Dettinger, 2012: Historical and national perspectives on extreme West Coast precipitation associated with atmospheric rivers during December 2010. Bull. Amer. Meteor. Soc., 93, 783-790, doi:10.1175/BAMS-D-11-00188.1.

, P. J. Neiman, and G. A. Wick, 2004: Satellite and CALJET aircraft observations of atmospheric rivers over the eastern North Pacific Ocean during the winter of 1997/98. Mon. Wea. Rev., 132, 1721-1745, doi:10.1175/1520-0493(2004)132<1721: $\mathrm{SACAOO}>2.0 . \mathrm{CO} ; 2$.

,,--- S. I. Gutman, M. D. Dettinger, D. R. Cayan, and A. B. White, 2006: Flooding on California's Russian River: Role of atmospheric rivers. Geophys. Res. Lett., 33, L13801, doi:10.1029/2006GL026689.

Rienecker, M. M., and Coauthors, 2011: MERRA: NASA's ModernEra Retrospective Analysis for research and applications. J. Climate, 24, 3624-3648, doi:10.1175/JCLI-D-11-00015.1.

Rivière, G., 2011: A dynamical interpretation of the poleward shift of the jet streams in global warming scenarios. J. Atmos. Sci., 68, 1253-1272, doi:10.1175/2011JAS3641.1.

Rutz, J. J., and W. J. Steenburgh, 2012: Quantifying the role of atmospheric rivers in the interior western United States. Atmos. Sci. Lett., 13, 257-261, doi:10.1002/asl.392.

_ - _ and F. M. Ralph, 2014: Climatological characteristics of atmospheric rivers and their inland penetration over the western United States. Mon. Wea. Rev., 142, 905-921, doi:10.1175/MWR-D-13-00168.1.

Ryoo, J.-M., D. E. Waliser, D. W. Waugh, S. Wong, E. J. Fetzer, and I. Fung, 2015: Classification of atmospheric river events on the U.S. West Coast using a trajectory model. J. Geophys. Res. Atmos., 120, 3007-3028, doi:10.1002/2014JD022023.

Saha, S., and Coauthors, 2010: The NCEP Climate Forecast System Reanalysis. Bull. Amer. Meteor. Soc., 91, 1015-1057, doi:10.1175/2010BAMS3001.1.

Scoccimarro, E., G. Villarini, M. Vichi, M. Zampieri, P. G. Fogli, A. Bellucci, and S. Gualdi, 2015: Projected changes in intense precipitation over Europe at the daily and subdaily time scales. J. Climate, 28, 6193-6203, doi:10.1175/JCLI-D-14-00779.1.

Sherwood, S. C., S. Bony, and J.-L. Dufresne, 2014: Spread in model climate sensitivity traced to atmospheric convective mixing. Nature, 505, 37-42, doi:10.1038/nature12829.

Siler, N., and G. Roe, 2014: How will orographic precipitation respond to surface warming? An idealized thermodynamic perspective. Geophys. Res. Lett., 41, 2606-2613, doi:10.1002/ 2013 GL059095.

Singh, M. S., and P. A. O'Gorman, 2014: Influence of microphysics on the scaling of precipitation extremes with temperature. Geophys. Res. Lett., 41, 6037-6044, doi:10.1002/2014GL061222.

Swart, N. C., and J. C. Fyfe, 2012: Observed and simulated changes in the Southern Hemisphere surface westerly wind-stress. Geophys. Res. Lett., 39, L16711, doi:10.1029/ 2012GL052810.

van Vuuren, D., and Coauthors, 2011: The representative concentration pathways: An overview. Climatic Change, 109, 5-31, doi:10.1007/s10584-011-0148-z.

Woollings, T., A. Hannachi, and B. Hoskins, 2010: Variability of the North Atlantic eddy-driven jet stream. Quart. J. Roy. Meteor. Soc., 136, 856-868, doi:10.1002/qj.625.

Yin, J. H., 2005: A consistent poleward shift of the storm tracks in simulations of 21st century climate. Geophys. Res. Lett., 32 , L18701, doi:10.1029/2005GL023684.

Zelinka, M. D., S. A. Klein, and D. L. Hartmann, 2012: Computing and partitioning cloud feedbacks using cloud property histograms. Part II: Attribution to changes in cloud amount, altitude, and optical depth. J. Climate, 25, 3736-3754, doi:10.1175/ JCLI-D-11-00249.1.

Zhu, Y., and R. E. Newell, 1998: A proposed algorithm for moisture fluxes from atmospheric rivers. Mon. Wea. Rev., 126, 725-735, doi:10.1175/1520-0493(1998)126<0725:APAFMF>2.0.CO;2. 